\title{
Plus ca change...
}

Book review by Annebella Pollen, New Formations 74, 2011, pp.134-137

Risto Sarvas and David M. Frohlich, From Snapshots to Social Media: The Changing Picture of Domestic Photography (Springer, 2011)

With backgrounds in Human-Computer Interaction, Risto Sarvas and David M. Frohlich have a distinctive take on the study of photography, yet in From Snapshots to Social Media: The Changing Picture of Domestic Photography they set themselves a challenge. Attempting to find a "middle ground" between interaction design research, which they find "technology-centric", and the Cultural Studies-influenced Visual Culture, they aim to address perceived imbalances between these differing approaches in their survey of domestic photography by drawing together literature from both sides. The authors argue, in their favour, that photography studies are inherently interdisciplinary, stating "Few systems have had the privilege of being studied in the arts and humanities, engineering, design, the social sciences and business studies". (p. 183) With an awareness that "issues such as privacy, power, social structures and economic factors are almost missing from design-oriented science and engineering research" and that "historical, cultural and political contexts are often absent" from technology studies, (p. 3) this book is their attempt to provide historical and cultural photographic context for their intended readership: "researchers, engineers, and designers of digital imaging technologies, social media, and Web services or other products relying on mediated social interaction." (p. 2)

The authors pursue this aim by following a structure that sections the history of photographic technology into three consecutive periods, which they label 'The Portrait Path (ca. 1830s-1890s)', 'The Kodak Path (ca. 1888-1990s)' and 'The Digital Path (ca. 1990- )', but not before they have spent a chapter defending their approach. Arguing for a Kuhnian model based on an understanding that technological changes are non-linear, non-cumulative and non-incremental, but are instead based on paradigm shifts, they posit that changes in media come about cyclically. They state that change begins when established technological patterns are disrupted, leading to an "era of ferment", and ending with a new path "characterised by a dominant design". (p. 14) At pains to defend this method from accusations of technological determinism, they spend some time in the early chapters of the book detailing what they are not claiming: that "the inherent qualities of the technology are the sole determiners of the path". (p. 18) They state that reductionist historical readings, and a lack of attention to social and economic factors, has led to the creation of technological myths, particularly in relation to Kodak, and that this is an approach that they will be careful to avoid. 
It is rather frustrating, then, that the historical chapters that follow seem to adopt precisely this approach. Chapters 3 and 4, covering domestic photographic technology from the 1830s to 1990s, reproduces much of the commonly held consensus about photography's origins and establishment. Those with knowledge of this territory will find little that is new here, apart from occasional retrospective and sometimes contentious assertions, for example, that "profile pictures in online social networking services have the same function as cartes [de visite] in demonstrating specific social stratum or a subculture" (p. 37) or that the ability for a camera owner to take their own photograph, as a result of growth in camera ownership in the late nineteenth century, was "usergenerated content over a century ago". (p.60) Generally, however, this teleological technological approach rather smoothes over photographic history, particularly in relation to photography's consumption and use, which is conspicuously under-considered. The structure of 'paths' could be defended as no more than a practical organising strategy aimed at managing an extended period of history into two short chapters if it was not for the occurrence of such deterministic statements such as "The Portrait Path was going to end, and the Kodak Path was beginning" (p. 44) and "The camera, named Kodak, was ready to change photography forever". (p. 51) These early sections of the book function largely as an extended literature review, and one that is content to take its sources at face value. For example, it is claimed that the Kodak "way of photography" was domestic alone. The authors state, "'Kodakers' did not take photographs for news purposes, to create art, to shape public opinions, to present themselves for a public audience, to sell pictures, or simply to partake in public discourses", yet a quick consultation of Amateur Photographer magazine, for example, from the early decades of the twentieth century, would have revealed that a whole range of practices and purposes for popular photography coexisted with the domestic, from 'record' photographs with historical aims to pictorialist images with aesthetic ambitions, as well as those intended for competition, exhibition and beyond. This lack of nuance is further exacerbated in the excessively rapid coverage of the period from the turn of the twentieth century through to the 1960s. Whilst it is convenient for the authors' later argument for digital photography's complexity to claim that "The Kodak model did not change for a century, and the role of technology in this model changed very little as well" (p. 66) statements such as "People born at the beginning of the twentieth century would witness technological marvels such as a man walking on the moon and aeroplanes but see no radical change in photography in their entire lifetime" $(p .80)$ are so sweeping as to be unsupportable.

Moving into Chapter 5, which considers 'The Digital Path' from 1990, the authors must take a different approach, not least because their admitted former method of drawing on "milestone" histories (p. 83) cannot continue when so few exist. As the authors note, little research was 
conducted into the early days of digital photographic technologies; additionally, convenient trajectories of progress are not possible in an era still in ferment. It is in this chapter, and particularly the following one, that the authors are clearly on more comfortable territory, and the literature that they draw on is much more recent, less well-known, and at times of their own making. Necessarily drawn from a range of locations to cover all aspects of new technology and its uses, sources such as marketing reports, journalism, social science studies, and research and development user trials bring together a range of voices to assess patterns in digital photographic technology and uptake. Chapter 6, 'Digital Photo Adoption', is perhaps the strongest of the volume. Detailed and empiricallygrounded research into a wide range of "current photo ecologies" is provided in order to examine a key question, that is, "whether the digital revolution has changed the very nature of photography and why we perform it". (p. 103) Building on the foundational research into popular photographic practice established by authors such as Chalfen (1), Sarvas and Frohlich attempt to establish whether the principal motivations for personal photographic practice remain rooted in practices of memory, identity and communication despite changing media forms.

While the authors acknowledge that a number of small changes are apparent in domestic digital photography - the curator of family photographs may be more likely to be the teenage child rather than the mother; digital photographs are more concerned with immediacy of communication than memorialisation and reflection - there are a number of areas where, despite all of the popular rhetoric of digital "revolution", continuity in practice is most strongly evident. These include the amusing observation that generally digital photographs are still kept in a state of disorganisation despite users' "misplaced faith in the power of digital technology to help them organise their images" (p. 108), and the interesting assertion that photo-sharing, despite its technological neologism, remains more pervasive in practice off-line than on-line. The authors note that "conventional methods of display" (in the form of printed photo products, from posters and photobooks) are "historically more established and better supported than ever before with digital printing technology". (p.121)

So far, so similar, then. Where changes are more significant, however (and the observations most fascinating), is in the use of personal photographs in social media. Despite the vast quantities of photographs circulating on platforms such as Facebook (hosting 48 billion images from some 500 million users globally), the authors observe that, surprisingly, there is an almost total lack of research into this area, and thus must infer conclusions of their own. As the core business model of Facebook is to sell targeted advertising space through social interaction (where demographic information, including age, gender, home town, religion, politics and education, is provided by the user), personal 
photographs function to make the service attractive to people by helping to aid communication and establish identities, but also 'lock in' the user and provide the host company with saleable information about social networks and connections. The authors assert that risks in retrieval (e.g. the lack of security that Facebook will even exist in, say, twenty years' time) provide further evidence that immediacy of communication rather than memorialisation is the principal function of digital domestic photography. They also observe that the photographic industry - with its porous boundaries - now makes money less from selling consumables but from "selling advertising space and perpetually changing technology". (p. 171) Certainly, a fundamental movement from photography supported by a recognisable photographic industry to an ICT infrastructure is evident, and the authors admit that with new social media functions and 'cloud' computing facilities, "the meanings and definitions of both words in the term 'domestic photography' are somewhat outdated". (p. 184).

As an attempt to provide missing social, historical and critical context to studies of human-computer interaction, this book has an admirable purpose. In the close attention it pays to the diversity of digital photographic practice and through its thorough summaries of recent research in the area, it provides insightful appraisals and clearly identifies gaps for future study. Whether it will achieve its aim of fostering a closer collaboration between business development, product design and visual studies, however, remains open to question. For a reader with interests in the historical and cultural study of photography, rather than a technology designer, in order for the research to be fully satisfying there needs to be more challenge to terms used throughout, including interrogation of changing notions of domesticity, closer analysis of the wholly unquestioned category of 'snapshots', and more acknowledgement of the complex meanings, uses and applications of personal photographs pre-1990. As the authors repeatedly note, digital technology is fast changing and complex, and it is likely that the picture of domestic photography will continue to shift. It is a shame that the authors flatten nearly two centuries of photographic practice as a largely straightforward and stable trajectory in order to provide a foil for this upheaval.

(1) Richard Chalfen, Snapshot Versions of Life (Bowling Green, Ohio: Bowling Green University Press, 1987) 